\title{
INTERVAL EXPLOSION SEARCH ALGORITHM AND ITS APPLICATION TO HYPERSONIC AIRCRAFT MODELLING AND MOTION OPTIMIZATION PROBLEMS
}

\author{
A.V. Panteleev, Moscow Aviation Institute, Moscow, Russian Federation, \\ avpanteleev@inbox.ru, \\ V.N. Panovskiy, Moscow Aviation Institute, Moscow, Russian Federation, \\ panovskiy.v@yandex.ru,
}

T.I. Korotkova, Moscow Aviation Institute, Moscow, Russian Federation, tatyanamail11@yandex.ru

\begin{abstract}
This work considers hypersonic aircraft open-loop control problem in a presence of terminal and phase constraints. By the discretization process this problem is transformed into a nonlinear programming problem which is solved numerically by the interval explosion search algorithm. This algorithm belongs to metaheuristic algorithms of interval global optimization. Desired control is constructed in a class of interval piecewise-constant and piecewise-linear functions. Also this work demonstrates the comparison of results obtained by the proposed method and by Galerkin projection technique. This comparison confirms the efficiency of the interval based control algorithm.

Keywords: interval analysis; interval explosion search; optimization; optimal control; hypersonic aircraft.
\end{abstract}

\section{Introduction}

Development of hypersonic aerial vehicle (HAV) control techniques is very urgent field of applied cybernetics [1]. One of possible opportunities consists in spaceplane creation. Spaceplane is a special type of spacecraft which can soar and hurtle as an ordinary plane. In consequence of principally different interaction between HAV and atmosphere all proposed methods should be analyzed accurately to find out advantages and disadvantages. To raise accuracy it is important to develop new numerical methods using metaheuristc and interval optimization algorithms [1-3], which can give an appropriate solution for the HAV optimal open-loop control problem.

Existing numerical methods of optimal control include various methods which use Pontryagin's maximum principle and Bellman's equation, direct methods (e.g. gradient methods, first-ordered methods), second-ordered methods which are based on a Taylor appoximation of Krotov - Bellman function, different improvement methods and etc. $[4,5]$. There is a need in development of new approaches in order to improve the efficiency and accuracy. Such an approach consists in the use of interval analysis coupled with metaheuristic strategies $[2,3]$.

Interval analysis [6-10] is used as the main component of interval explosion search (IES). Existing interval optimization methods can be divided into a few groups:

- methods of unconstrained optimization (Moore - Skelboe algorithm, Ichida - Fujii algorithm, Dussel algorithm, interval simulated annealing, graph subdivision method and etc. [11-13]),

- methods of constrained optimization (Hansen method, Moore method and etc. [7,9]). 
IES belongs to the group of so called metaheuristic algorithms. Metaheuristic algorithms give admissible solutions in the most practically significant cases. Such algorithms do not guarantee obtaining the best solution, but the main advantage is that they have lower computational complexity. Thus they can be applied to complicated problems without additional constraints on problem statement (differentiability, convexity and etc.). Also these methods do not use necessary and sufficient optimality conditions [1]. Metaheuristic algorithms combine one or several heuristic procedures which base on the higher level strategy.

In the following work it will be shown how general open-loop control problem can be transformed into the form of interval constrained global optimization problem which will be solved numerically with the IES. Method efficiency is demonstrated on the solution of HAV optimal control problem.

\section{Interval Analysis. Definitions and Notations}

The main idea of interval analysis [6-10] is that real numbers are surrounded with intervals and real vectors - with interval vectors, or boxes. Hereafter, lowercase letters in square brackets $\left([a]=\left[a_{l} ; a_{u}\right]\right)$ will be used to denote intervals and bold lowercase letters in square brackets $\left([\mathbf{a}]=\left[a_{1}\right] \times \ldots \times\left[a_{n}\right]\right)$ - for boxes.

Each interval has the following characteristics:

- lower bound: $[a]=\sup \{\xi \in \mathbb{R} \cup\{-\infty, \infty\} \mid \forall \zeta \in[a]: \xi \leq \zeta\}$;

- upper bound: $\overline{\overline{[a]}}=\inf \{\xi \in \mathbb{R} \cup\{-\infty, \infty\} \mid \forall \zeta \in[a]: \zeta \leq \xi\}$;

- width of nonempty interval: $\omega([a])=\overline{[a]}-[a]$;

- midpoint of nonempty and finite interval: $\operatorname{mid}([a])=\frac{[a]+\overline{[a]}}{2}$.

The same parameters are defined for boxes. Lower and upper bounds and midpoint become vectors, width is now calculated as maximum of component's widths.

Interval hull of a set $X \subset \mathbb{R}^{n}$ is the smallest box (box with minimum width) $[\mathbf{X}]$, that contains $X$. If the set is surrounded by square brackets it means that we consider the interval hull.

Let $\circ$ be a binary operation, then $[x] \circ[y]=\left[\left\{\xi_{1} \circ \xi_{2} \mid \xi_{1} \in[x], \xi_{2} \in[y]\right\}\right]$; let $f$ be an unary operator, then $f([x])=[\{f(\xi) \mid \xi \in[x]\}]$.

The set of intervals is designated by $\mathbb{I R}$, set of boxes - by $\mathbb{I} \mathbb{R}^{n}$. Consider a function $f$ from $\mathbb{R}^{n}$ to $\mathbb{R}$. The interval function $[f]$ from $\mathbb{I} \mathbb{R}^{n}$ to $\mathbb{R}$ is an inclusion function for $f$ if $\forall[x] \in \mathbb{I}^{n}, f([x]) \subset[f]([x])$. Inclusion function allows to get a priori estimate of function's range even if it is nonconvex or disconnected. If all variables are substituted with intervals and all operations are done by the rules of interval arithmetic such a value is called an estimation of a direct function image.

\section{Interval $\varepsilon$-Minimization Problem}

Consider a given box $[\mathbf{s}]$ and a cost function $f: \mathbb{R}^{n} \rightarrow \mathbb{R}$. Interval $\varepsilon$-minimization problem consists in determination of such a box $[\mathbf{p}]^{*} \subset[\mathbf{s}]$ that

$$
\omega\left([\mathbf{p}]^{*}\right) \leq \varepsilon, \nexists[\mathbf{x}] \subseteq[\mathbf{s}], \omega([\mathbf{x}]) \geq \varepsilon, \overline{[f]([\mathbf{x}])}<\underline{[f]\left([\mathbf{p}]^{*}\right)}
$$

where the value $\varepsilon$ affects the width of the $[\mathbf{p}]^{*}$ box. 


\section{Strategy of Interval Explosion Search (IES)}

During the initialization bombs are randomly placed on the search area. Each bomb is associated with the box which describes its location. Moreover, all bombs are sorted (by ascending) by the lower bound of its direct function image estimation. IES has two iterative phases (Fig. 1): global and refining search, which differ from each other by the explosion procedure realization. Each iterative phase consists of:

1) bomb power calculation (power vector affects splinter scatter radius),

2) explosion procedure (during this procedure each bomb produces two splinters (new interval vectors) which scatter into different directions),

3) bomb list renewal.

Algoritm terminates when the maximum number of iterations is exceeded. From the bomb list we choose the one with the minimum lower bound of its direct function image estimation.

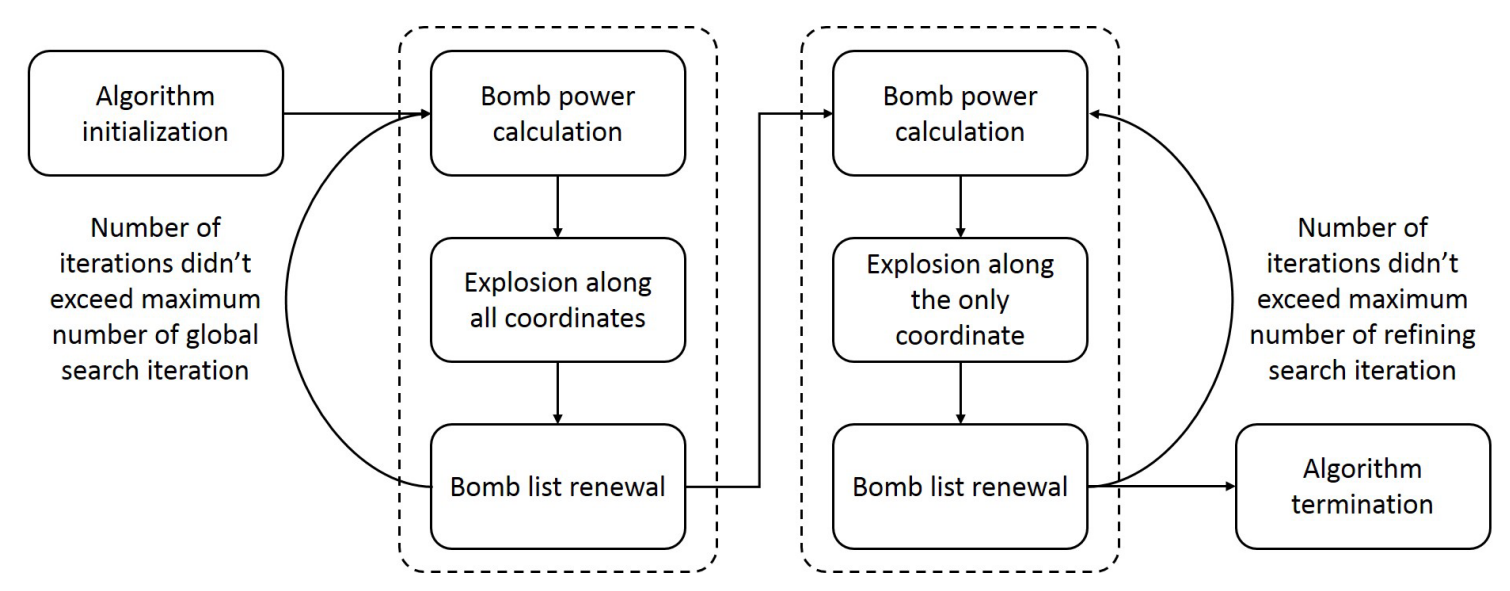

Fig. 1. IES strategy

\section{IES Algorithm}

Step 1. Set iteration number $t^{g}=0$, maximum number of global and refining search $t_{\max }^{g}$ and $t_{\max }^{c}$, maximum number of bombs $B_{\max }$, power vector $r_{\max } \in \mathbb{R}^{n}$, search area $[\mathbf{s}]$ and $\varepsilon=2^{-\frac{t_{\max }^{g}+t_{\max }^{c}}{n}} \cdot \omega([\mathbf{s}])$.

Step 2. Randomly distribute bombs (interval vectors) on the search area: $\left\{[\mathbf{b}]=\left[\xi_{1} ; \zeta_{1}\right] \times \ldots \times\left[\xi_{n} ; \zeta_{n}\right]\right\}_{i=1}^{B_{\max }}$, where $\xi_{j}$ and $\zeta_{j}$ are random numbers which are uniformly distributed over interval $\left[s_{j}\right]$ (if $\xi_{j}>\zeta_{j}$, then the corresponding interval is substituted with the interval $\left.\left[\zeta_{j} ; \xi_{j}\right]\right)$. Sort bombs by ascending of the lower bound of the direct function image estimation.

Step 3. Bomb power calculation. For each bomb $[\mathbf{b}]_{i}$ from the list calculate its power vector: $p^{i}=\frac{i-1}{B_{\max }-1} \cdot r_{\max }, i=1, \ldots, B_{\max }$.

Step 4. Explosion (global search). During this step each bomb produces two splinters by the bisection procedure. Bisection is a division along the widest component [8]. Thus 
we obtain two new bombs from the given one: $[\mathbf{b}]_{i}=\left(\left(\begin{array}{c}{\left[b_{1}\right]_{i}} \\ \vdots \\ {\left[b_{k}\right]_{i}} \\ \vdots \\ {\left[b_{n}\right]_{i}}\end{array}\right)+\left(\begin{array}{c}\xi\left(-p_{1}^{i} ; p_{1}^{i}\right) \\ \vdots \\ \xi\left(0 ; p_{k}^{i}\right) \\ \vdots \\ \xi\left(-p_{n}^{i} ; p_{n}^{i}\right)\end{array}\right)\right) \cap[\mathbf{s}]$ and $[\mathbf{b}]_{B_{\max }+i}=\left(\left(\begin{array}{c}{\left[b_{1}\right]_{i}} \\ \vdots \\ {\left[b_{k}\right]_{i}} \\ \vdots \\ {\left[b_{n}\right]_{i}}\end{array}\right)+\left(\begin{array}{c}\xi\left(-p_{1}^{i} ; p_{1}^{i}\right) \\ \vdots \\ \xi\left(-p_{k}^{i} ; 0\right) \\ \vdots \\ \xi\left(-p_{n}^{i} ; p_{n}^{i}\right)\end{array}\right)\right) \cap[\mathbf{s}]$, where $\xi(a ; b)$ is a random variable uniformly distributed on interval $[a ; b], k=\operatorname{Arg} \max _{j=1, \ldots, n} \omega\left(\left[b_{j}\right]_{i}\right)$.

Step 5. Bomb list renewal. On the previous step number of bombs has been doubled. Thus unnecessary ones should be removed: sort bombs in ascending order by the lower bound of the direct function image estimation. Remove last $B_{\max }$ bombs.

Step 6. Increase $t^{g}$ by 1 . If $t^{g}<t_{\max }^{g}$ then return to step 3, otherwise go to step 7 .

Step 7. Set iteration number $t^{c}=0$.

Step 8. Bomb power calculation. For each bomb $[\mathbf{b}]_{i}$ from the list calculate its power vector: $p^{i}=\frac{i-1}{B_{\max }-1} \cdot r_{\max }, i=1, \ldots, B_{\max }$.

Step 9. Explosion (refining search). During this step each bomb produces two splinters by the bisection procedure. Bisection is a division along the widest component [8]. Thus we obtain two new bombs from the given one: $[\mathbf{b}]_{i}=\left(\left(\begin{array}{c}{\left[b_{1}\right]_{i}} \\ \vdots \\ {\left[b_{k}\right]_{i}} \\ \vdots \\ {\left[b_{n}\right]_{i}}\end{array}\right)+\left(\begin{array}{c}0 \\ \vdots \\ \xi\left(0 ; p_{k}^{i}\right) \\ \vdots \\ 0\end{array}\right)\right) \cap[\mathbf{s}]$ and $[\mathbf{b}]_{B_{\max }+i}=\left(\left(\begin{array}{c}{\left[b_{1}\right]_{i}} \\ \vdots \\ {\left[b_{k}\right]_{i}} \\ \vdots \\ {\left[b_{n}\right]_{i}}\end{array}\right)+\left(\begin{array}{c}0 \\ \vdots \\ \xi\left(-p_{k}^{i} ; 0\right) \\ \vdots \\ 0\end{array}\right) \cap[\mathbf{s}], k=\operatorname{Arg} \max _{j=1, \ldots, n} \omega\left(\left[b_{j}\right]_{i}\right)\right.$.

Step 10. Bomb list renewal. Sort bombs in ascending order by the lower bound of the direct function image estimation. Remove last $B_{\max }$ bombs.

Step 11. Increase $t^{c}$ by 1 . If $t^{c}<t_{\max }^{c}$ then return to step 8, otherwise go to step 12 .

Step 12. Choose the box which is associated with the bomb with the smallest lower bound of the direct function image estimation as a problem solution $[\mathbf{p}]^{*}$. Find $[f]\left([\mathbf{p}]^{*}\right)$ as a cost function interval.

\section{Optimal Open-Loop Control of Continuous Deterministic Systems}

Behaviour of control object is described by differential equation [16]:

$$
\dot{x}(t)=f(t, x(t), u(t)),
$$


where $t \in T=\left[t_{0} ; t_{1}\right]$ is continuous time, $T$ is the system operational time, $x \in \mathbb{R}^{n}$ is the system state vector, $u \in[\mathbf{u}] \subset \mathbb{R}^{q}$ is a control vector, [u] is a set of admissible control values (box), $f(t, x, u)=\left(f_{1}(t, x, u), \ldots, f_{n}(t, x, u)\right)^{T}$ is a continuous vector-function.

Initial state is given

$$
x\left(t_{0}\right)=x_{0} .
$$

Terminal state $x\left(t_{1}\right)$ should satisfy the following interval terminal conditions:

$$
\Gamma_{i}\left(x\left(t_{1}\right)\right) \in\left[G_{i}\right], i=1, \ldots, l,
$$

where $0 \leq l \leq n,\left[G_{i}\right]$ are given intervals, functions $\Gamma_{i}(x)$ are continuously differentiable, system of vectors $\left\{\frac{\partial \Gamma_{i}(x)}{\partial x_{1}}, \ldots, \frac{\partial \Gamma_{i}(x)}{\partial x_{n}}\right\}, i=1, \ldots, l$ is linearly independent $\forall x \in \mathbb{R}^{n}$.

The only information which is used to form control is continuous time $t$. Hence we consider open-loop control.

Set of admissible processes $D\left(t_{0}, x_{0}\right)$ is defined as a set of pairs $d=(x(\cdot), u(\cdot))$ which include trajectory $x(\cdot)$ and admissible control $u(\cdot)$, where $\forall t \in T: u(t) \in[\mathbf{u}]$ and state equation (2), initial condition (3) and terminal condition (4) are satisfied.

On the set of admissible processes we consider cost functional

$$
I(d)=\int_{t_{0}}^{t_{1}} f(t, x(t), u(t)) d t+F\left(x\left(t_{1}\right)\right)
$$

where $f^{0}(t, x, u)$ and $F(x)$ are given continuous functions.

In order to transofrm the given problem into a problem without terminal constraints (4) we can use penalty function:

$$
\bar{I}(d)=I(d)+\sum_{i=1}^{l} R_{i}^{(1)} \cdot H_{i}^{(1)}
$$

where $H_{i}^{(1)}=h_{\infty}^{2}\left(\left[\Gamma_{i}\left(x\left(t_{1}\right)\right) ; \Gamma_{i}\left(x\left(t_{1}\right)\right)\right],\left[G_{i}\right]\right), h_{\infty}([a],[b])=\inf \{r \mid[a] \subset[b]+[-r ; r]\}$ is a Hausdorff metric, $R_{i}^{(1)}$ are penalty parameters.

If there are interval phase constraints $\left\{p_{j}(x(t), u(t), \dot{x}(t), \dot{u}(t)) \in\left[P_{j}\right], \forall t \in T\right\}_{j=1}^{N_{p}}$, where $p_{j}(\cdot)$ is the constraint function, $\left[P_{j}\right]$ are given intervals, $N_{p}$ is the number of constraints, then we have another form of modified cost functional (5):

$$
\bar{I}(d)=I(d)+\sum_{i=1}^{l} R_{i}^{(1)} \cdot H_{i}^{(1)}+\sum_{j=1}^{N_{p}} R_{j}^{(2)} \cdot H_{j}^{(2)}
$$

where

$$
H_{j}^{(2)}=\int_{t_{0}}^{t_{1}} h_{\infty}^{2}\left(\left[p_{j}(x(t), u(t), \dot{x}(t), \dot{u}(t)) ; p_{j}(x(t), u(t), \dot{x}(t), \dot{u}(t))\right],\left[P_{j}\right]\right) d t
$$

$R_{j}^{(2)}$ are penalty parameters.

The problem is to find such a pair $d^{*}=\left(x^{*}(\cdot), u^{*}(\cdot)\right)=\arg \min _{d \in D\left(t_{0}, x_{0}\right)} I(d)$. 


\section{Application of Interval Optimization Technique}

We will consider interval control as a piecewise-constant or piecewise-linear interval function $[u](t)$ and interval trajectory as a piecewise-continuous interval function which satisfies $(2)-(4)$.

The piecewise-constant control (Fig. 2 (a)) can be uniquely associated with an interval vector $\underbrace{\left[u_{1}\left(\tau_{0}\right)\right] \times \ldots \times\left[u_{q}\left(\tau_{0}\right)\right]}_{\left[u\left(\tau_{0}\right)\right]} \times \ldots \times \underbrace{\left[u_{1}\left(\tau_{N-1}\right)\right] \times \ldots \times\left[u_{q}\left(\tau_{N-1}\right)\right]}_{\left[u\left(\tau_{N-1}\right)\right]}$, where $\tau_{i}=t_{0}+\frac{t_{1}-t_{0}}{N} \cdot i$, and $N$ is number of discretization steps. Corresponding interval control can be found as follows: $[u](t) \in\left[u\left(\tau_{i}\right)\right], \tau_{i} \leq t<\tau_{i+1}, i=0, \ldots, N-1$.

The piecewise-linear control (Fig. 2 (b)) can be uniquely associated with an interval vector $\underbrace{\left[u_{1}\left(\tau_{0}\right)\right] \times \ldots \times\left[u_{q}\left(\tau_{0}\right)\right]}_{\left[u\left(\tau_{0}\right)\right]} \times \ldots \times \underbrace{\left[u_{1}\left(\tau_{N}\right)\right] \times \ldots \times\left[u_{q}\left(\tau_{N}\right)\right]}_{\left[u\left(\tau_{N}\right)\right]}$. Corresponding interval control can be found as follows: $[u](t) \in \frac{\tau_{i+1}-t}{\tau_{i+1}-\tau_{i}} \cdot\left[u\left(\tau_{i}\right)\right]+\frac{t-\tau_{i}}{\tau_{i+1}-\tau_{i}} \cdot\left[u\left(\tau_{i+1}\right)\right], \tau_{i} \leq t<\tau_{i+1}$, $i=0, \ldots, N-1$.
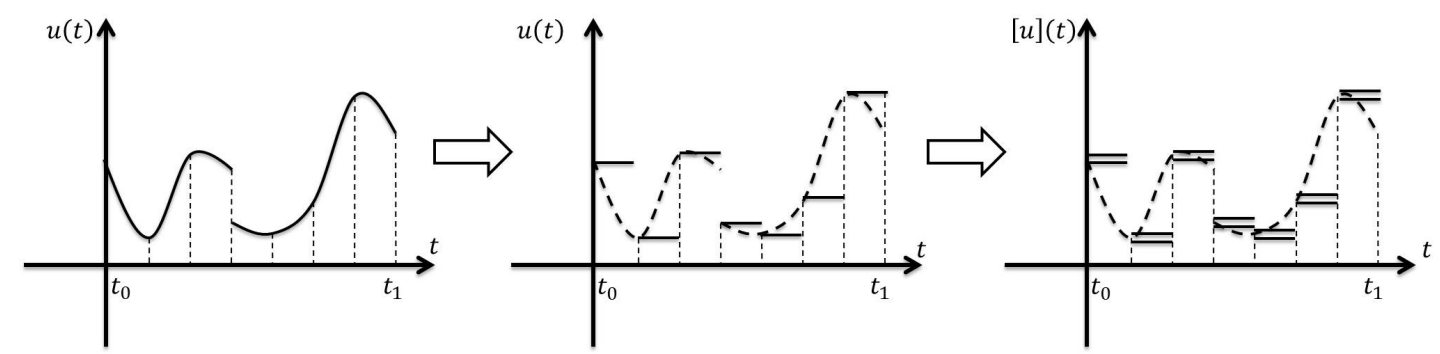

(a)
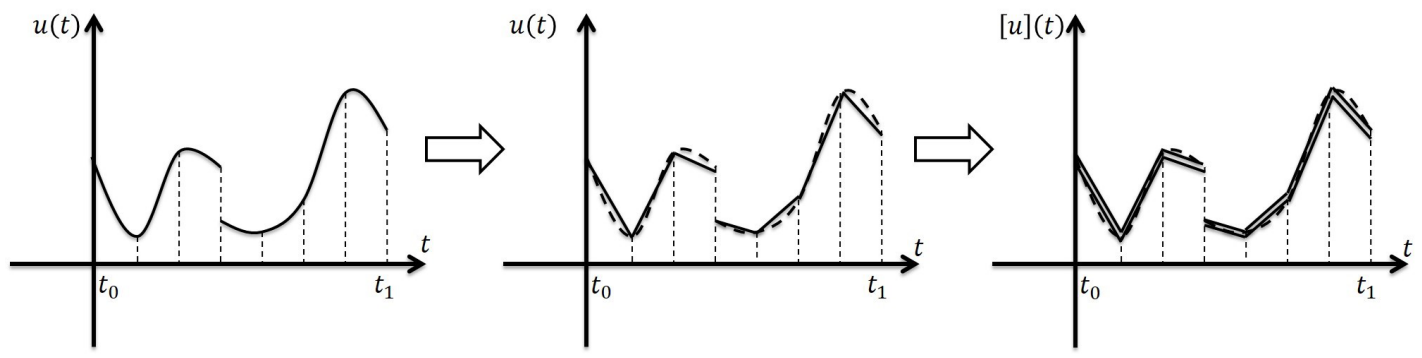

(b)

Fig. 2. Piecwise-continuous interval control

It is suggested to find the interval vector, which satisfies condition (1), by the IES algorithm (optimization will be done on the search area $[\mathbf{s}]=\underbrace{[\mathbf{u}] \times \ldots \times[\mathbf{u}]}_{q \cdot N}$ for the piecewise-constant interval control and $[\mathbf{s}]=\underbrace{[\mathbf{u}] \times \ldots \times[\mathbf{u}]}_{q \cdot(N+1)}$ for the piecewise-linear interval control).

The value of the cost function criterion (14) is calculated by the numerical methods using Euler, Euler - Cauchy or Runge - Kutta formulas [3] (all calculations on the right hand side of equations are done by the rules of interval arithmetic [6-10]. 


\section{HAV Optimal Open-Loop Control Problem}

Consider the following system of differential equations [17] which describes HAV landing process:

$$
\left\{\begin{array}{c}
\dot{r}(t)=V \cdot \sin \gamma, \\
\dot{\phi}(t)=\frac{V \cdot \cos \gamma \cdot \sin \psi}{r}, \\
\dot{\gamma}(t)=\frac{L \cdot \cos \sigma}{m \cdot V}+\left(\frac{V}{r}-\frac{g}{V}\right)+2 \cdot \Omega \cdot \cos \phi \cdot \cos \psi+ \\
+\frac{\Omega^{2} \cdot t}{V} \cdot \cos \phi \cdot(\cos \gamma \cdot \cos \phi+\sin \gamma \cdot \sin \phi \cdot \sin \psi), \\
\dot{\theta}(t)=\frac{V \cdot \cos \gamma \cdot \cos \psi}{r \cdot \cos \phi}, \\
\dot{V}(t)=\frac{-D}{m}-g \cdot \sin \gamma+\Omega^{2} \cdot t \cdot \cos \phi \cdot(\sin \gamma \cdot \cos \phi-\cos \gamma \cdot \sin \phi \cdot \sin \psi), \\
\dot{\psi}(t)=\frac{L \cdot \sin \sigma}{m \cdot V \cdot \cos \gamma}-\frac{V}{r} \cdot \cos \gamma \cdot \cos \psi \cdot \tan \phi+2 \cdot \Omega \cdot(\tan \gamma \cdot \cos \phi \cdot \sin \psi-\sin \phi)- \\
-\frac{\Omega^{2} \cdot t}{V \cdot \cos \gamma} \cdot \sin \phi \cdot \cos \phi \cdot \cos \psi,
\end{array}\right.
$$

where $r$ is the distance from the Earth center, $\theta$ is the longitude, $\phi$ is the latitude, $V$ is the Earth-relative velocity, $\gamma$ is the flight path slope, $\psi$ is the velocity azimuth angle, $\sigma$ is the roll angle, $g=\frac{G M}{r^{2}}$ is the acceleration, $G M$ is the Earth gravitational constant, $\Omega$ is the Earth rotational velocity, $m$ is the HAV mass, $L=\frac{1}{2} \cdot \rho_{0} \cdot e^{-\beta \cdot\left(r-r_{0}\right) \cdot} V^{2} \cdot C_{L} \cdot S_{\text {ref }}$ is the aerodynamic lift force, $D=\frac{1}{2} \cdot \rho_{0} \cdot e^{-\beta \cdot\left(r-r_{0}\right)} \cdot V^{2} \cdot C_{D} \cdot S_{\text {ref }}$ is the aerodynamic drag force, $\rho_{0}$ is the sea-level air density, $\beta$ is the numerical coefficient, $\rho_{0}$ is the numerical constant, $C_{L}, C_{D}$ are the aerodynamic force coefficients, $S_{r e f}$ is the HAV surface area.

The aerodynamic force coefficients are defined by a polinomial function of Mach number $M=\frac{V}{V_{s}}\left(V_{s}\right.$ is sonic velocity) and attack angle $\alpha$ basing on $\mathrm{X}-33$ project information:

$$
\begin{gathered}
C_{L}=-0,0005225 \cdot \alpha^{2}+0,03506 \cdot \alpha-0,04857 \cdot M+0,1577 \\
C_{D}=0,0001432 \cdot \alpha^{2}+0,00558 \cdot \alpha-0,01048 \cdot M+0,2204 .
\end{gathered}
$$

The numerical parameters which are used in the model: $m=35828 \mathrm{~kg}, S_{\text {ref }}=149,3881$ $\mathrm{m}^{2}, \rho_{0}=1,2256 \mathrm{~kg} / \mathrm{m}^{3}, r_{0}=1,2256 \mathrm{~m}, \beta=0,00013785 \mathrm{~m}^{-1}, G M=3,986 \cdot 10^{14} \mathrm{~m}^{3} / \mathrm{s}^{2}$, $\Omega=0,000072722 \mathrm{rad} / \mathrm{s}, R_{e}=6378100 \mathrm{~m}, V_{e}=11180 \mathrm{~m} / \mathrm{s}$.

The state vector consists of 6 components: $x(t)=(r(t), \theta(t), \phi(t), V(t) \gamma(t), \psi(t))^{T}$. The HAV control is realized by attack and roll angles: $u(t)=(\alpha(t), \sigma(t))^{T}$.

The initial state of the system: $r\left(t_{0}\right)=6429100, \theta\left(t_{0}\right)=-85, \phi\left(t_{0}\right)=30, V\left(t_{0}\right)=$ $2600, \gamma\left(t_{0}\right)=-1,3, \psi\left(t_{0}\right)=0$.

The HAV control vector:

$$
u(t)=(\alpha(t), \sigma(t)) \in[-10 ; 50] \times[-80 ; 80], \forall t \in T=[0 ; 530] .
$$

The terminal conditions:

$$
\begin{array}{cc}
r\left(t_{1}\right) \in[6378578 ; 6378822], & V\left(t_{1}\right) \in[91,44 ; 91,44], \\
\theta\left(t_{1}\right) \in[-80,7126 ;-80,7098], & \gamma\left(t_{1}\right) \in[-6 ;-6], \\
\phi\left(t_{1}\right) \in[29,998903 ; 30,001097], & \psi\left(t_{1}\right) \in[-60 ;-60] .
\end{array}
$$

The HAV trajectory phase constraints:

$$
\begin{aligned}
& q(t) \in[0 ; 14364,1], \quad h(t)=r(t)-R_{e} \in[0 ; 121920], \quad V(t) \in[0,3 ; 5200], \\
& Q(t) \in[0 ; 242000], \quad \theta(t) \in[-90 ; 90], \quad \gamma(t) \in[-89 ; 89], \\
& n_{z}^{g}(t)=\frac{n_{z}(t)}{g} \in[-2,5 ; 2,5], \quad \phi(t) \in[-89 ; 89], \quad \psi(t) \in[-180 ; 180],
\end{aligned}
$$


where $q=\frac{1}{2} \cdot \rho_{0} \cdot e^{-\beta\left(r-r_{0}\right)} \cdot V^{2}$ is the dynamic pressure, $Q=4,477228 \cdot 10^{-9} \sqrt{\rho_{0} \cdot e^{-\beta \cdot\left(r-r_{0}\right)}}$. $V^{3,15}$ is the heat rate, $n_{z}=\frac{|L \cdot \cos \alpha+D \cdot \sin \alpha|}{m}$ is normal acceleration.

The constraints on control vector rate:

$$
\begin{aligned}
& \dot{\alpha}(t) \in[-5 ; 5] \Leftrightarrow \frac{\alpha\left(\tau_{i+1}\right)-\alpha\left(\tau_{i}\right)}{\tau_{i+1}-\tau_{i}} \in[-5 ; 5], \\
& \dot{\sigma}(t) \in[-5 ; 5] \Leftrightarrow \frac{\sigma\left(\tau_{i+1}\right)-\sigma\left(\tau_{i}\right)}{\tau_{i+1}-\tau_{i}} \in[-5 ; 5] .
\end{aligned}
$$

The cost functional for the given problem:

$$
\bar{I}(d)=\sum_{i=1}^{6} R_{i}^{(1)} \cdot H_{i}^{(1)}+\sum_{j=1}^{11} R_{j}^{(2)} \cdot H_{j}^{(2)},
$$

where $R_{1}^{(1)}=1000, R_{2}^{(1)}=R_{3}^{(1)}=R_{5}^{(1)}=R_{6}^{(1)}=1000000, R_{4}^{(1)}=10000$ and $R_{1}^{(2)}=R_{4}^{(2)}=$ $R_{7}^{(2)}=R_{8}^{(2)}=10, R_{2}^{(2)}=R_{3}^{(2)}=R_{5}^{(2)}=R_{6}^{(2)}=R_{9}^{(2)}=10000, R_{10}^{(2)}=R_{11}^{(2)}=1$.

It is required to find time histories of attack and roll angles, which minimize cost functional (14).

IES was implemented in a software complex, Visual Studio IDE and C\# programming language. Parameters of the IES: $t_{\max }^{g}=t_{\max }^{c}=2500, B_{\max }=100, r_{\max }=0,05$ for each dimension.

Charts on Fig. 3 show the results from [17] which were obtained by B-splines and Galerkin projection technique.
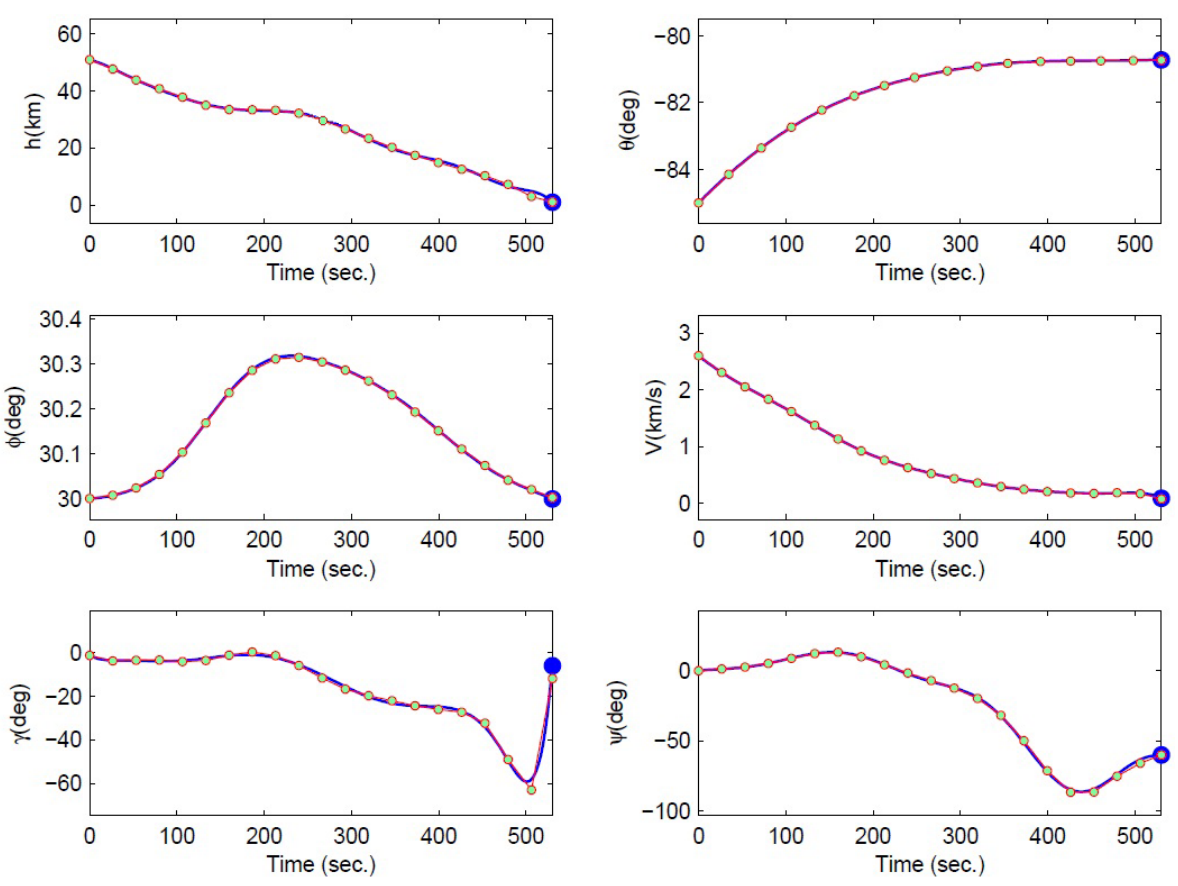

Fig. 3. State vector components

Charts on Fig. 4, show the results for the piecewise-constant interval control.

Charts on Fig. 5 show the results for the piecewise-linear interval control.

Information about constraints satisfaction are represented in Tables 1, 2.

Thus, by comparison of the results we can conclude that IES algorithm can be efficiently applied to HAV optimal open-loop control problem. Obviously it is better to 

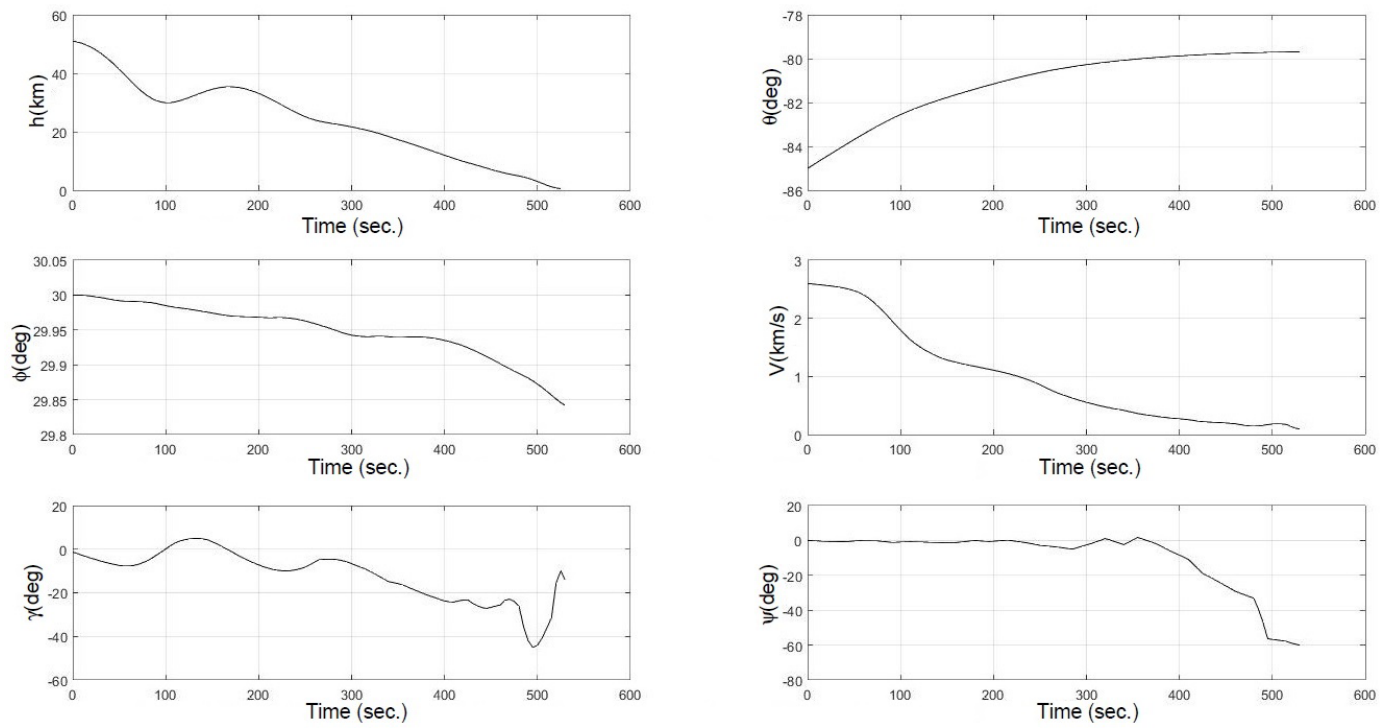

Fig. 4. State vector components
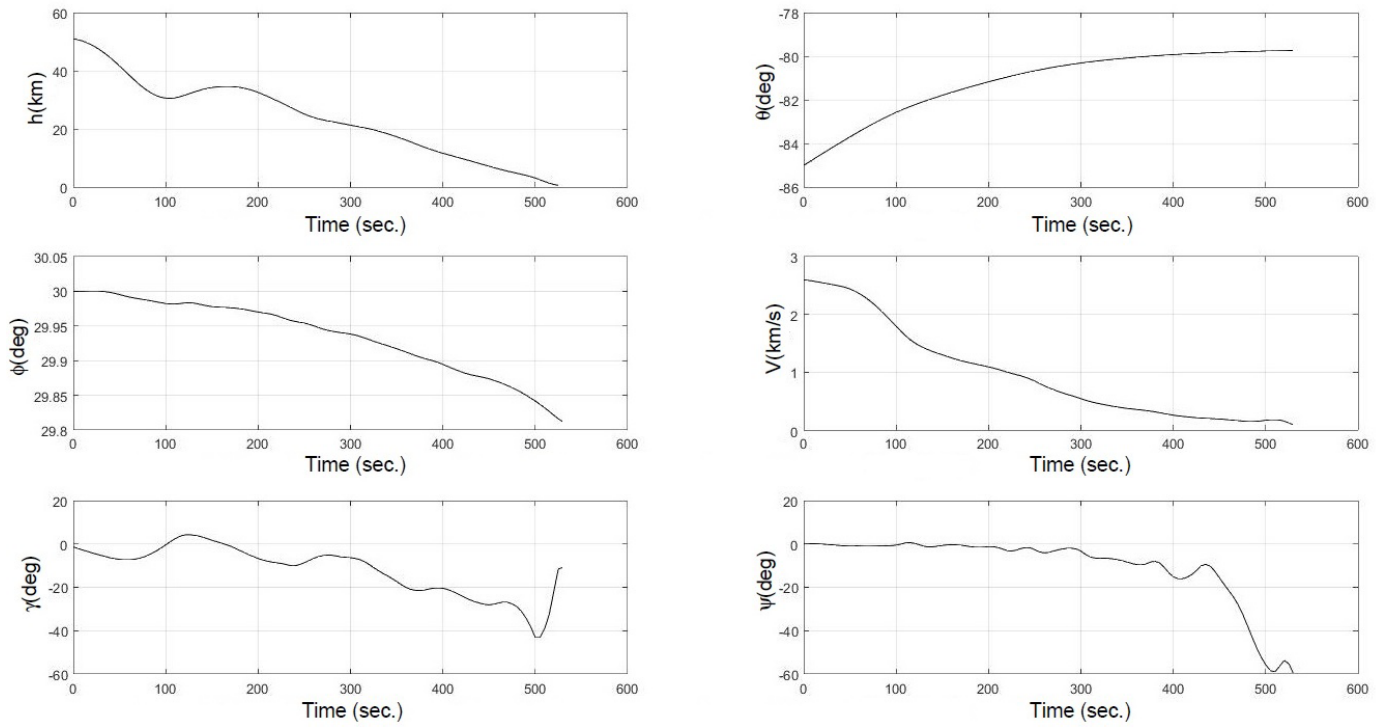

Fig. 5. State vector components

use piecewise-linear control to satisfy constraints more accurately. All terminal and phase constraints were satisfied accurately enough.

\section{Conclusion}

In the present work IES algorithm based on metaheuristics and interval analysis is considired. The HAV optimal open-loop control problem is solved. Obtained results are compared with the results obtained by Galerkin projection technique.

Acknowledgements. Research was supported by RFBR in the framework of scientific projects No. 16-31-00115 mol_a, No. 16-07-00419 A. 
$\frac{0}{\frac{0}{0}}$

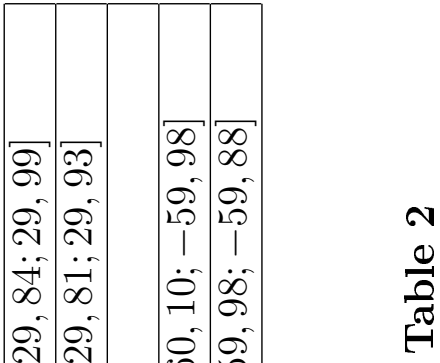

$N$
0
$\frac{0}{0}$

\begin{tabular}{|c|c|c|c|c|c|c|c|}
\hline 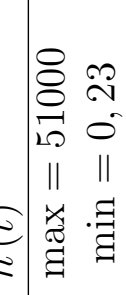 & 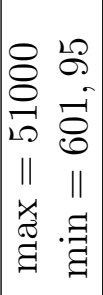 & $\frac{\underset{\varpi}{\sigma}}{\tau}$ & 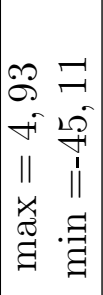 & 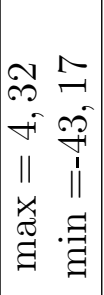 & & & \\
\hline 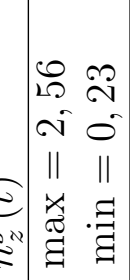 & 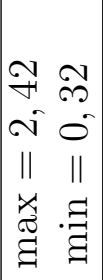 & $\begin{array}{c}\Xi \\
D\end{array}$ & 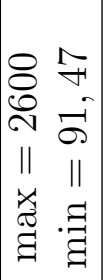 & 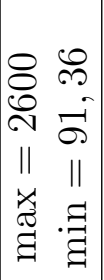 & $\underset{\cdot 0}{\Xi}$ & 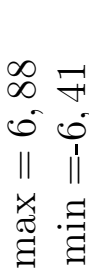 & 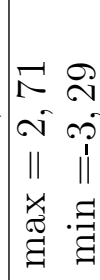 \\
\hline 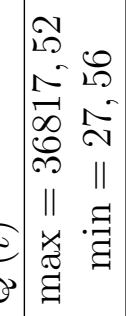 & 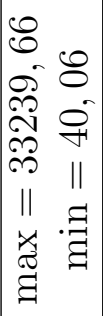 & $\frac{\Xi}{\theta}$ & 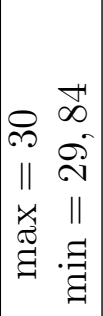 & 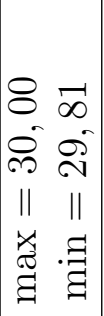 & $\underset{\cdot \circlearrowright}{Ð}$ & 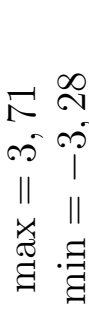 & 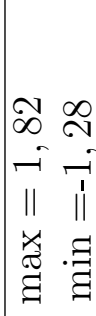 \\
\hline 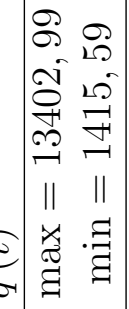 & 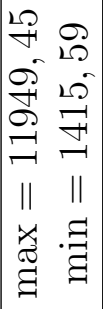 & $\underset{\infty}{\circledast}$ & 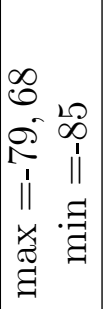 & 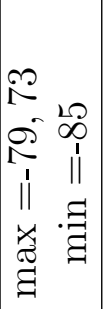 & $\begin{array}{l}Ð \\
2\end{array}$ & 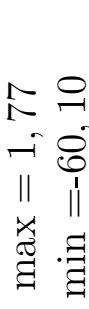 & 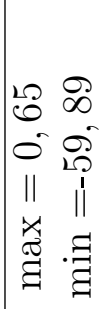 \\
\hline 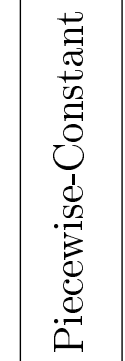 & 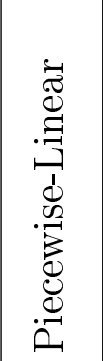 & & 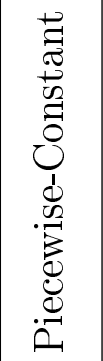 & 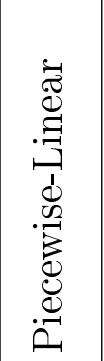 & & 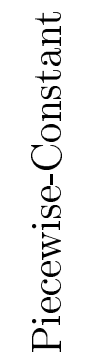 & 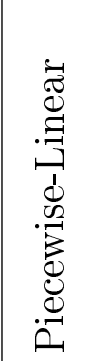 \\
\hline
\end{tabular}




\section{References}

1. Panteleev A.V. Metody optimizatsii [Optimization Methods]. Moscow, Logos, 2011.

2. Panteleev A.V. Metody global'noy optimizatsii. Metaevristicheskie strategii $i$ algoritmy [Methods of Global Optimization. Metaheuristic Strategies and Algorithms]. Moscow, Vuzovskaya kniga, 2013.

3. Panteleev A.V. Primenenie evolyutsionnykh metodov global'noy optimizatsii $v$ zadachakh optimal'nogo upravleniya determinirovannymi sistemami [Application of Evolutional Methods of Global Optimization to Optimal Determined Systems Control Problems]. Moscow, Izd-vo MAI, 2013.

4. Gurman B.I. [Evolution and Prospects of Approximate Methods of Optimal Control]. Program Systems: Theory and Applications, 2001, no. 2 (6), pp. 11-29.

5. Fedorenko R.P. Priblizhennoe reshenie zadach optimal'nogo upravleniya [Approximate Solution of Optimal Control Problems]. Moscow, Nauka, 1978.

6. Shary S.P. Konechnomernyy interval'nyy analiz [Finite-Dimensional Interval Analysis]. Novosibirsk, XYZ, 2010.

7. Hansen E. Global Optimization Using Interval Analysis. N.Y., Marcel Dekker, 2004.

8. Jaulin L. Applied Interval Analysis. London: Springer, 2001. DOI: 10.1007/978-1-4471-0249-6

9. Moore R.E. Interval Analysis. Englewood Cliffs, Prentice Hall, 1966.

10. Moore R.E. Methods and Applications of Interval Analysis. Philadelphia, SIAM, 1979. DOI: $10.1137 / 1.9781611970906$

11. Ratschek H. New Computer Methods for Global Optimization. Chichester, Horwood, 1988.

12. Shary S.P. A Surprising Approach in Interval Global Optimization. Reliable Computing, 2001, no. 7 , pp. $497-505$.

13. Shary S.P. Randomized Algorithms in Interval Global Optimization. Numerical Analysis and Applications, 2008, no. 1, pp. 376-389.

14. Panovskiy V.N. [Interval Genetic Algorithm of Global Constrained Optimization]. Uspekhi sovremennoy radioelektroniki [Achievements of Modern Radioelectronics], 2014, no. 4, pp. $71-75$.

15. Panovskiy V.N. Prikladnoe primenenie interval'nogo metoda vzryvov [Application of Interval Explosion Search]. Trudy MAI [MAI Proceedings], 2014, no. 73, 21 p.

16. Panteleev A.V. Teoriya upravleniya v primerakh i zadachakh [Control Theory in Examples and Problems]. Moscow, Vysshaya shkola, 2003.

17. Singh B. Optimal Guidance of Hypersonic Vehicles Using B-Splines and Galerkin Projection. Guidance Navigation and Control Conference and Exhibit, 2008, no. AIAA-2008-7263.

Received April 1, 2016

Вестник ЮУрГУ. Серия «Математическое моделирование 


\title{
ИНТЕРВАЛЬНЫЙ МЕТОД ВЗРЫВОВ И ЕГО ПРИМЕНЕНИЕ К ЗАДАЧЕ МОДЕЛИРОВАНИЯ И ОПТИМИЗАЦИИ ДВИЖЕНИЯ ГИПЕРЗВУКОВОГО ЛЕТАТЕЛЬНОГО АППАРАТА
}

\author{
А.В. Пантелеев, В.Н. Пановский, Т.И. Короткова
}

\begin{abstract}
Рассматривается задача поиска оптимального программного управления гиперзвуковым летательным аппаратом при наличии терминальных и фазовых ограничений. С помощью процедуры дискретизации она сводится к задаче нелинейного программирования, которая решается с помощью интервального метода взрывов, относящегося к метаэвристическим алгоритмам интервальной глобальной оптимизации. Искомое управление ищется в классе интервальных кусочно-постоянных и кусочнолинейных функций. Приведено сравнение полученных результатов с известным в задаче управления конечным положением гиперзвукового летательного аппарата, свидетельствующее об эффективности предложенного подхода.

Ключевые слова: интервальный анализ; интервальный метод взрывов; оптимизация; оптимальное управление; гиперзвуковой летательный аппарат.
\end{abstract}

Исследование выполнено при финансовой поддержке РФФИ в рамках научных проектов № 16-31-00115 мол_а, № 16-07-00419 A.

\section{Литература}

1. Пантелеев, А.В. Методы оптимизации / А.В. Пантелеев, Т.А. Летова. - М.: Логос, 2011.

2. Пантелеев, А.В. Методы глобальной оптимизации. Метаэвристические стратегии и алгоритмы / А.В. Пантелеев, Д.В. Метлицкая, Е.А. Алешина. - М.: Вузовская книга, 2013.

3. Пантелеев, А.В. Применение эволюционных методов глобальной оптимизации в задачах оптимального управления детерминированными системами / А.В. Пантелеев. - М.: Издво МАИ, 2013.

4. Гурман, В.И. Эволюция и перспективы приближенных методов оптимального управления / В.И. Гурман, И.В. Расина, А.О. Блинов // Программные системы: теория и приложения. - 2001. - № 2 (6). - С. 11-29.

5. Федоренко, Р.П. Приближенное решение задач оптимального управления / Р.П. Федоренко. - М.: Наука, 1978.

6. Шарый, С.П. Конечномерный интервальный анализ / С.П. Шарый. - Новосибирск: XYZ, 2010.

7. Hansen, E. Global Optimization Using Interval Analysis / E. Hansen. - N.-Y.: Marcel Dekker, 2004.

8. Jaulin, L. Applied Interval Analysis / L. Jaulin, M. Kieffer, O. Didrit, E. Walter. - London: Springer, 2001.

9. Moore, R.E. Interval Analysis / R.E. Moore. - Englewood Cliffs: Prentice Hall, 1966.

10. Moore, R.E. Methods and Applications of Interval Analysis / R.E. Moore. - Philadelphia: SIAM, 1979.

11. Ratschek, H. New Computer Methods for Global Optimization / H. Ratschek. - Chichester: Horwood, 1988. 
12. Shary, S.P. A Surprising Approach in Interval Global Optimization / S.P. Shary // Reliable Computing. - 2001. - № 7. - P. 497-505

13. Shary, S.P. Randomized Algorithms in Interval Global Optimization / S.P. Shary // Numerical Analysis and Applications. - 2008. - № 1. - P. 376-389

14. Пановский, В.Н. Интервальный генетический алгоритм глобальной условной оптимизации / В.Н. Пановский // Успехи современной радиоэлектроники. - 2014. - № 4. C. $71-75$.

15. Пановский, В.Н. Прикладное применение интервального метода взрывов / В.Н. Пановский // Труды МАИ. - 2014. - № 73. - 21 с.

16. Пантелеев, А.В. Теория управления в примерах и задачах / А.В. Пантелеев, А.С. Бортаковский. - М.: Высшая школа, 2003.

17. Singh, B. Optimal Guidance of Hypersonic Vehicles Using B-Splines and Galerkin Projection / B. Singh, R. Bhattacharya // Guidance Navigation and Control Conference and Exhibit. 2008. - № AIAA-2008-7263.

Андрей Владимирович Пантелеев, доктор физико-математических наук, профессор, кафедра «Математическая кибернетика», Московский авиационный институт (г. Москва, Российская Федерация), avpanteleev@inbox.ru.

Валентин Николаевич Пановский, аспирант, кафедра «Математическая кибернетика», Московский авиационный институт (г. Москва, Российская Федерация), panovskiy.v@yandex.ru.

Короткова Татьяна Ивановна, доктор физико-математических наук, професcop, кафедра «Математическая кибернетика», Московский авиационный институт (г. Москва, Российская Федерация), tatyanamail11@yandex.ru.

Поступила в редакцию 1 апреля 2016 г. 